Anatomie des Menschen

Zweiter Teil 


A. Waldeyer $\dagger$
A. Mayet

\section{Anatomie des Menschen}

für Studierende und Ärzte dargestellt nach systematischen, topographischen und praktischen Gesichtspunkten

Zweiter Teil: Kopf und Hals $\cdot$ Auge $\cdot$ Ohr $\cdot$ Gehirn $\cdot$ Arm $\cdot$ Brust

15., neubearbeitete Auflage

Walter de Gruyter

Berlin · New York 1986 
Prof. Dr. med. et phil. A. Waldeyer $\dagger$

ehemals Direktor des Anatomischen

Institutes der Humboldt-Universität Berlin,

unter Mitarbeit von

Dr. med. U. Waldeyer

ehemals 1. Oberärztin am Anatomischen Institut der Humboldt-Universität Berlin

Prof. Dr. med. A. Mayet,

Direktor des Anatomischen Institutes

der Johannes-Gutenberg-Universität

Saarstraße 21

6500 Mainz

Das Buch enthält 448 Abbildungen

CIP-Kurztitelaufnahme der Deutschen Bibliothek

Waldeyer, Anton:

Anatomie des Menschen : für Studierende u.

Ärzte dargest. nach systemat., topograph. u.

prakt. Gesichtspunkten / A. Waldeyer. A. Mayet.

[Unter Mitarb. von U. Waldeyer]. - Berlin ;

New York : de Gruyter

NE: Mayet, Anton [Bearb.]

Teil 2. - 15., neubearb. Aufl. - 1986.

ISBN 3-11-005734-4

(C) Copyright 1986 by Walter de Gruyter \& Co., Berlin 30. Alle Rechte, insbesondere das Recht der Vervielfältigung und Verbreitung sowie der Übersetzung, vorbehalten. Kein Teil des Werkes darf in irgendeiner Form (durch Photokopie, Mikrofilm oder ein anderes Verfahren) ohne schriftliche Genehmigung des Verlages reproduziert oder unter Verwendung elektronischer Systeme verarbeitet, vervielfältigt oder verbreitet werden. Printed in Germany.

Die Wiedergabe von Gebrauchsnamen, Handelsnamen, Warenbezeichnungen und dergleichen in diesem Buch berechtigt nicht zu der Annahme, daß solche Namen ohne weiteres von jedermann benutzt werden dürfen. Vielmehr handelt es sich häufig um gesetzlich geschützte, eingetragene Warenzeichen, auch wenn sie nicht eigens als solche gekennzeichnet sind.

Satz und Druck: Passavia Druckerei GmbH Passau.

Bindearbeiten: Lüderitz \& Bauer Buchgewerbe GmbH, Berlin.

Einbandgestaltung: R. Hübler, Berlin. 